\title{
O AQUÍFERO FRATURADO CRISTALINO EM UM SETOR DO AGRESTE PARAIBANO.
}

Lucas Emanuel Batista Oliveira ${ }^{1}$

Lucas Aguiar de Medeiros ${ }^{2}$

Paula Stein ${ }^{3}$

\author{
10.18190/1980-8208/estudosgeologicos.v31n1p3-15 \\ ${ }^{1}$ Mestrando do Programa de Pós-Graduação em Exploração Petrolífera e Mineral \\ (PPGEPM), Universidade Federal de Campina Grande (UFCG). Av. Aprígio Veloso, \\ 882, Campina Grande, PB, CEP 58109-970, Brasil. \\ E-mail: lucas.engdeminas@gmail.com \\ ${ }^{2}$ Unidade Acadêmica de Mineração e Geologia, Universidade Federal de Campina \\ Grande (UFCG). Av. Aprígio Veloso, 882, Bloco BY, Campina Grande, PB, CEP \\ 58109-970, Brasil. E-mail: lucasaguiar_@live.com \\ ${ }^{3}$ Programa de Pós-Graduação em Exploração Petrolífera e Mineral \\ (PPGEPM), Universidade Federal de Campina Grande (UFCG). Av. Aprígio Veloso, \\ 882, Campina Grande, PB, CEP 58109-970, Brasil. E-mail:paula.stein@gmail.com
}

\section{RESUMO}

No Estado da Paraíba, excetuando-se a região litorânea, predomina o clima semiárido e os tipos litológicos mais comuns são rochas ígneas e metamórficas, o que de um modo geral, conjuntamente, limita o armazenamento de água subterrânea. O presente trabalho teve como objetivo avaliar os aspectos que influenciam a presença de águas no aquífero fraturado em um setor do Agreste Paraibano, que se destaca do contexto regional de escassez, e desempenha um papel importante no suprimento local de água, sobretudo nos períodos de estiagem prolongada. Foram avaliados 180 poços em 9 municípios, captando águas do aquífero fraturado Cristalino, a partir da base de dados do SIAGAS (Sistema de Informações de Águas Subterrâneas) da CPRM (Serviço Geológico do Brasil). Os dados litológicos, de vazão e de salinidade das águas se integraram às informações de chuvas, cobertura vegetal e topografia. $\mathrm{Na}$ porção central da área, entre os municípios de Alagoa Nova, Areia e Pilões, a maior produtividade dos poços é acompanhada por águas predominantemente doces. Esse cenário possivelmente decorre da maior incidência de chuvas no setor e da presença de um manto de intemperismo mais espesso, associado a presença das rochas sedimentares da Formação Serra dos Martins, ambos sobrejacentes às rochas cristalinas do aquífero fraturado.

Palavras-chaves: Formação Serra dos Martins, salinidade, precipitação pluviométrica, águas subterrâneas.

\section{ABSTRACT}

In the State of Paraíba the semi-arid climate and the geology of igneous and metamorphic rocks dominate, imposes serous limitations concerning the storage of groundwater. This work aimed to evaluate the fractured aquifer in Agreste Paraibano environment. This region stands out from the regional context of scarcity and plays an important role in the supply of water in periods without rain. This work evaluated 180 wells located in the fractured aquifer, encompassing 9 municipalities. All the studied well was from the Groundwater Information System (SIAGAS) database of Geological Service of Brazil (CPRM). The lithological, flow and salinity data of the waters were integrated with information on rainfall, vegetation cover and topography. In the central 
portion of the area (Alagoa Nova, Areia and Pilões) the greater productivity of the wells is accompanied by predominantly sweet waters. This scenario is possibly due to the higher incidence of rainfall in the sector and the presence of a thicker mantle of weathering, associated with the presence of the sedimentary rocks of the Serra dos Martins Formation.

Keywords: Serra dos Martins Formation, salinity, rainfall, groundwater

\section{INTRODUÇÃO}

O Estado da Paraíba possui quase $80 \%$ do seu território inserido em clima semiárido (BRASIL, 2005), o que inibe a presença de rios perenes na região, sobretudo devido à baixa precipitação pluviométrica e elevada taxa de evaporação. Excetuando-se a região litorânea do Estado, os demais domínios, em sua plenitude, sofrem as consequências de uma estiagem severa que vem se alastrando nos últimos anos (ANA, 2017). Os tipos litológicos também não contribuem para o efetivo armazenamento de águas subterrâneas, na medida em que quase a totalidade do território paraibano se encontra sob o domínio de rochas ígneas e metamórficas, reconhecidamente de baixo potencial hidrogeológico, e comumente com qualidade das águas impróprias ao consumo humano e demais usos em função da sua salinidade normalmente elevada (Diniz et al., 2014). Aliado a esses atributos naturais, destaca-se a histórica ausência de políticas públicas voltadas a uma melhor eficiência no sistema de distribuição de águas, sobretudo nas regiões interioranas, o que faz com que parte da população recorra a sistemas alternativos de abastecimento hídrico, como a perfuração de poços particulares e/ou o comércio de caminhões tanque de água (carros pipa).

O presente estudo avalia uma porção do Agreste Paraibano, onde estão inseridos municípios que se destacam do contexto regional por manterem reservas subterrâneas mesmo nos períodos de estiagem prolongada. Esse setor é responsável pelo suprimento hídrico local, haja vista que 0 sistema público de abastecimento da CAGEPA (Companhia de Águas e Esgotos da Paraíba), até o período avaliado (ano de 2017), não vinham suprindo de forma eficiente a necessidade da população.

A área de estudo, com aproximadamente $1400 \mathrm{~km}^{2}$, abrange nove municípios das microrregiões do Brejo paraibano (Alagoa Grande, Alagoa Nova, Areia, Pilões e Serraria), Curimataú ocidental (Arara e Remígio), Esperança (Esperança) e Guarabira (Alagoinha) (MDA, 2010), geologicamente inseridos na Província Borborema (Fig.1). 


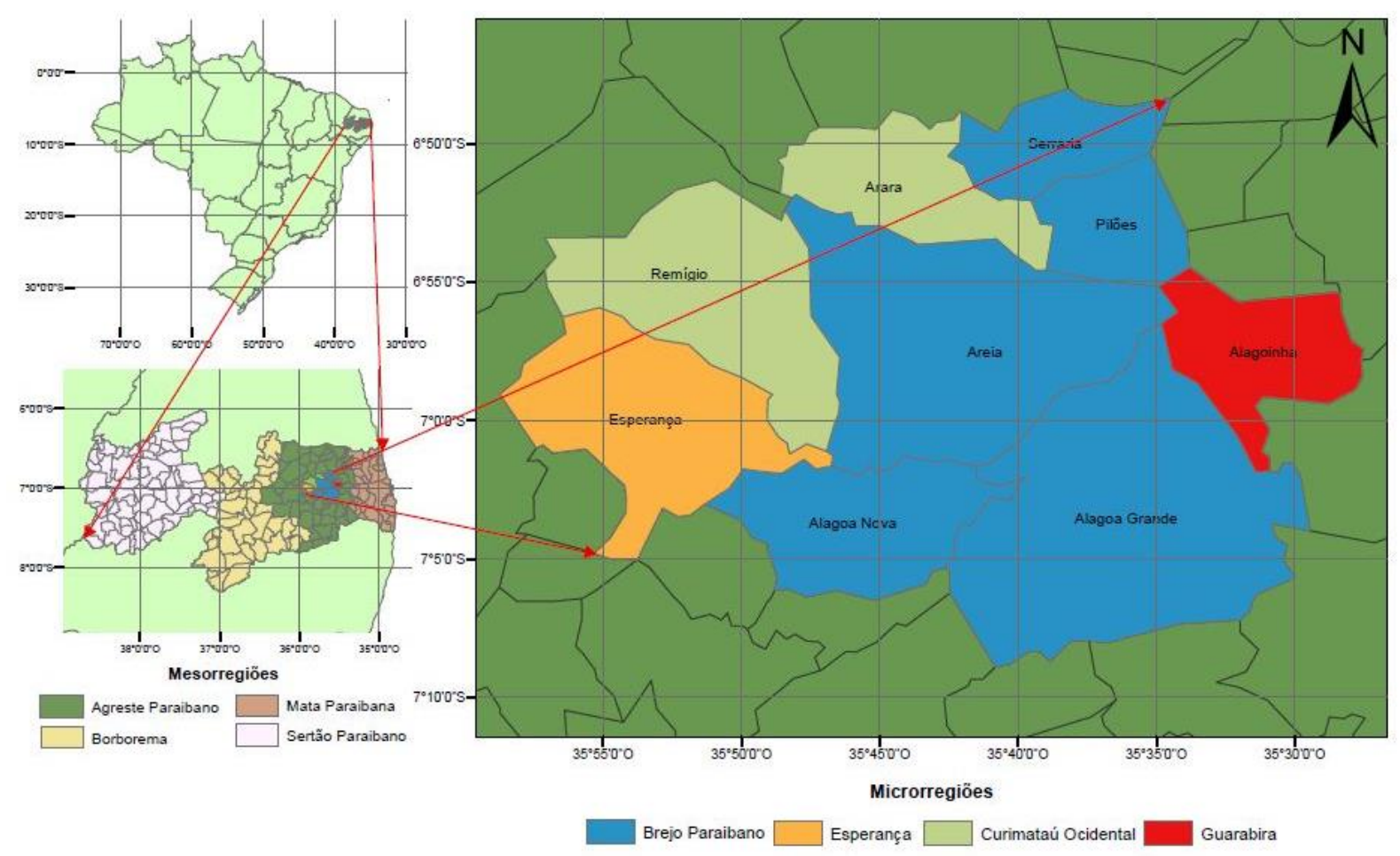

Figura 1 - Localização da área de estudo.

\section{MATERIAIS E MÉTODOS}

Um total de 180 poços captando águas do aquífero fraturado na área de estudo foi avaliado, mediante consulta na base de dados do SIAGAS (Sistema de Informações de Águas Subterrâneas) da CPRM (Serviço Geológico do Brasil) (CPRM, 2016). Desse montante, 47 poços apresentaram perfis litológicos e construtivos, que foram utilizados na elaboração de uma seção hidrogeológica simplificada, confeccionada no ambiente do software CorelDraw X5. As informações de vazão disponíveis em 109 poços subsidiaram uma estimativa da potencialidade hidrogeológica em cada município. A salinidade das águas subterrâneas, aferida a partir do parâmetro Sólidos Totais Dissolvidos (STD), foi medida in situ com auxílio de sonda multiparâmetros em 25 poços e nos demais 155 poços obtido da base do SIAGAS. Todos os resultados foram tratados estatisticamente e na forma gráfica utilizando o Microsoft Office Excel 2013, e a sua espacialização através de curvas de isovalores produzidas no software Arcgis v.10.4, utilizando o método do inverso do quadrado da distância para interpolação dos dados.

$\mathrm{Na}$ avaliação dos aspectos climáticos foram considerados os dados de precipitação pluviométrica, obtidos da AESA (Agência Executiva de Gestão das Águas do Estado da Paraíba) para o período de 1999 a 2005. O traçado da cobertura vegetal foi realizado com o auxílio das imagens de satélite do Google Earth datadas de 2014 e o das curvas de nível produzido a partir dados SRTM (Shuttle Radar Topography Mission). Todos os mapas foram confeccionados no Arcgis v.10.4.

\section{RESULTADOS E DISCUSSÕES}

Fatores Condicionantes

Aspectos fisiográficos 
As maiores incidências de chuvas foram registradas nos municípios de Areia, Pilões e Alagoinha, com médias anuais pluviométricas da ordem de 1370, 1260 e $1070 \mathrm{~mm}$, respectivamente (Fig. 2). Os municípios de Arara, Esperança e Serraria se destacaram pela reduzida média de chuvas, apresentando precipitação total anual de 591, 743 e $835 \mathrm{~mm}$, respectivamente. A dinâmica de ocorrência das chuvas na região deve-se ao efeito orográfico. O relevo da área, de um modo geral, aumenta de leste (cotas inferiores a $300 \mathrm{~m}$ ) para oeste (cotas superiores a $700 \mathrm{~m}$ ) (Fig. 3). Uma alteração abrupta na altitude é verificada na porção central da área de estudo em função da presença da Serra de Areia, localizada no município homônimo, que propicia instabilidade meteorológica e a ocorrência de chuvas no ápice da encosta da Serra, entre os municípios de Areia e Pilões. Essa situação provavelmente favorece 0 maior desenvolvimento da vegetação florestal (matas úmidas) no domínio central da área (Fig. 3), regionalmente conhecidas como Brejos de Altitude do Nordeste (Ab'Saber, 1970). Esse cenário de distribuição da precipitação sugere uma maior recarga local do aquífero no setor.

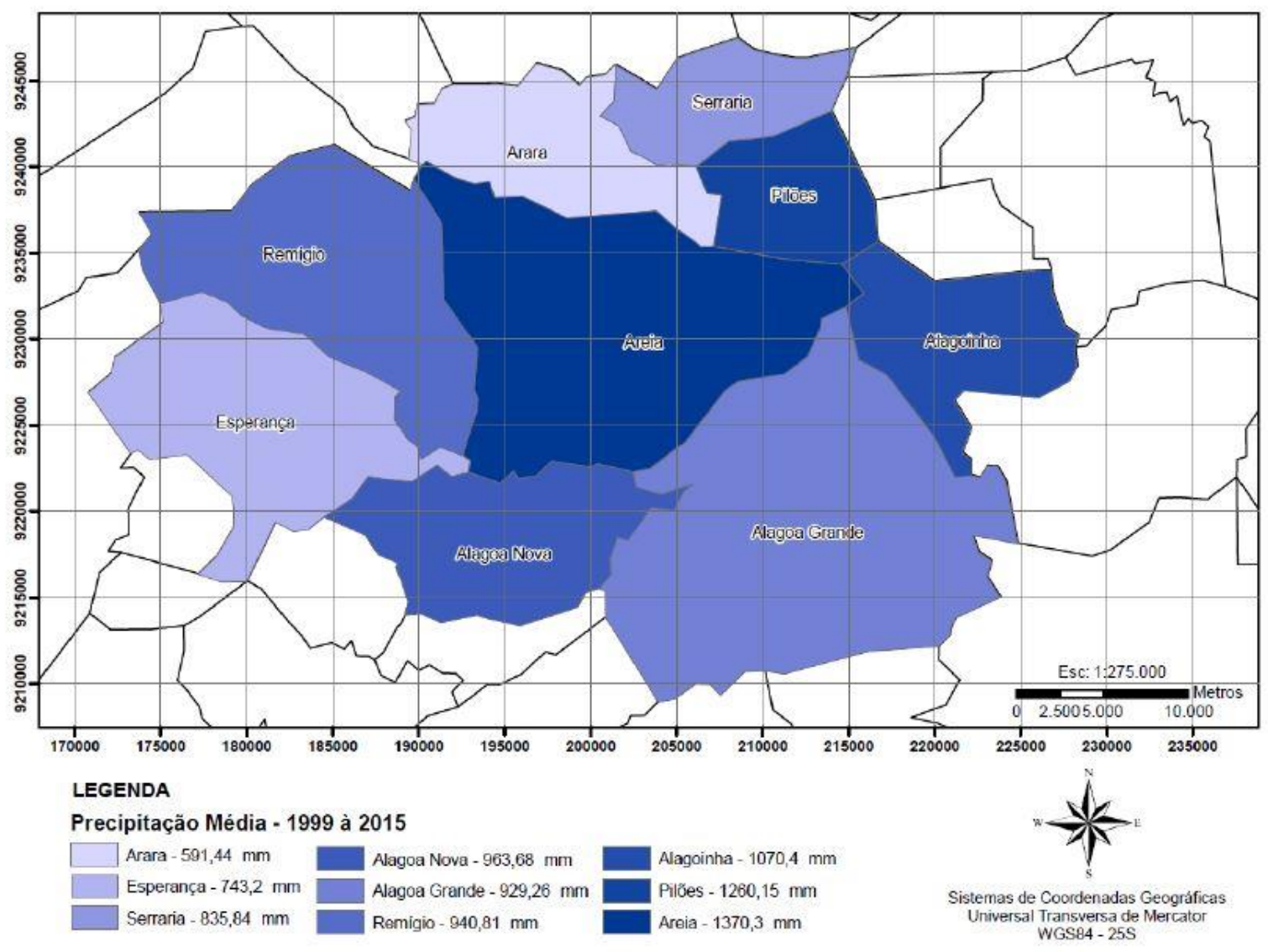

Figura 2 - Pluviometria média anual (período de 1999 a 2015) nos municípios investigados. Dados obtidos da AESA (2016). 


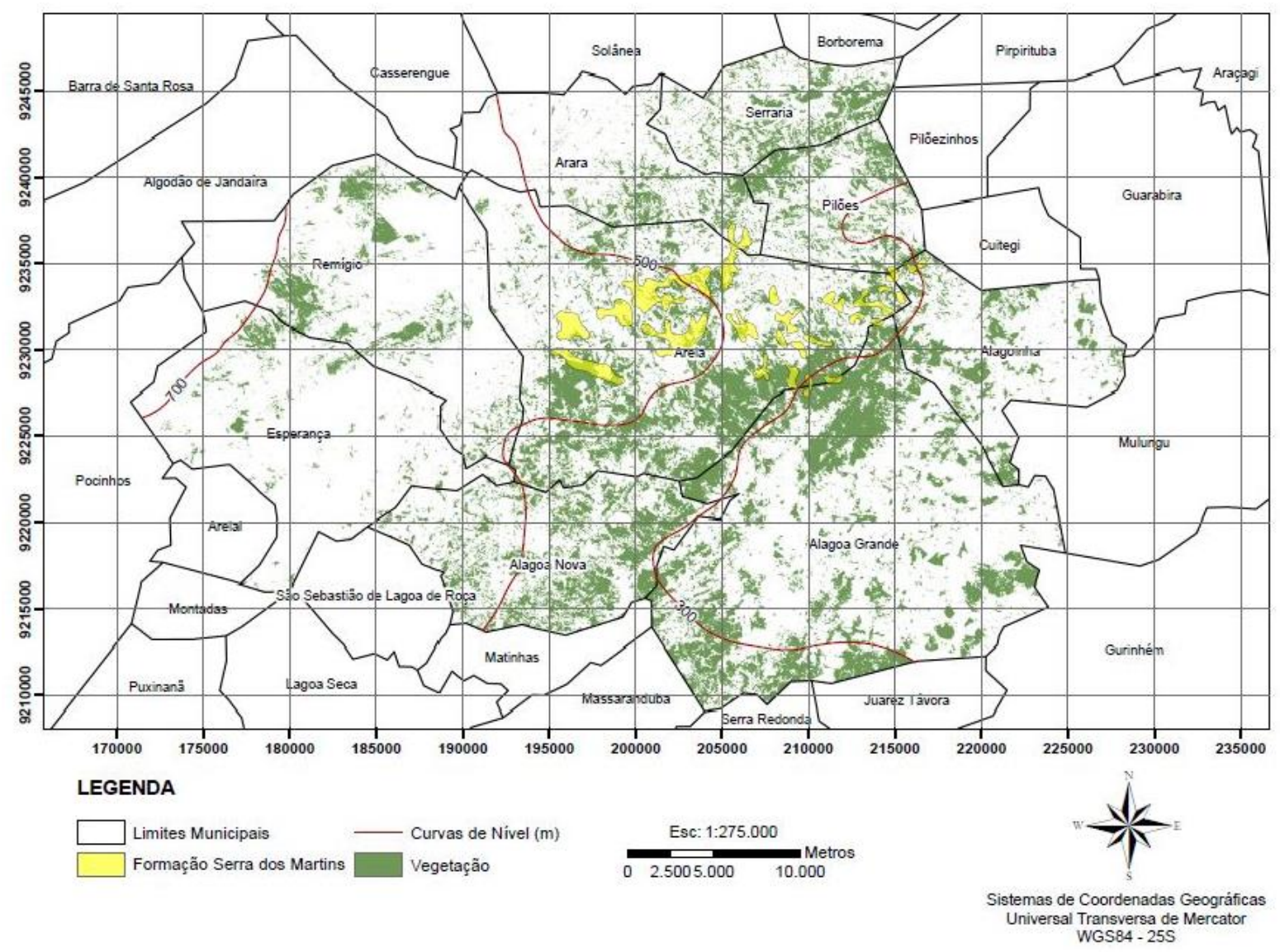

Figura 3 - Fragmentos florestais (cobertura vegetal) e topografia da área de estudo.

\section{Geologia e hidrogeologia}

Rochas

gnáissicas migmatizadas e ígneas plutônicas do embasamento cristalino constituem a principal unidade geológica da área de estudo (Santos \& Ferreira et al., 2002). Sobreposto a esta unidade, se desenvolve um manto de intemperismo (Fig. 4A), cujo a espessura aumenta de oeste para leste, de tal forma que no município de Remígio essa cobertura é da ordem de 5 metros e em Alagoinha pode atingir até 20 metros (Fig. 5).

$\mathrm{Na}$ porção central da área, no município de Areia, sobrejacente a sequência intemperisada, e muitas vezes ocorrendo de forma indiferenciada, aflora a Formação sedimentar Serra dos Martins (FSM). Regionalmente, essa formação constitui capeamentos remanescentes e ocorre na forma de platôs em cotas superiores a 600 metros (Menezes,
1999). De acordo com Almeida et al., (1969) data do Mioceno Superior ao Inferior (Paleógeno - Neógeno). Na área de estudo, a FSM ocorre como uma superfície residual descontínua no terreno, constituída por arenitos finos a médios, friáveis, de cor amarelaavermelhada, com presença de grãos quartzosos grossos sub-angulosos a arredondados (Fig. 4B). Comumente, na superfície ocorre na forma de uma crosta laterítica avermelhada, com seixos de quartzo angulosos.

Todos os poços investigados no presente estudo captam nas rochas do embasamento cristalino, onde se desenvolve 0 aquífero fraturado, regionalmente conhecido como aquífero Cristalino; de natureza anisotrópica e heterogênea, cuja água subterrânea encontra-se nas fendas e fraturas geralmente interconectadas. Do ponto de vista construtivo, as coberturas sedimentares, quando 
ocorrem, são isoladas mediante a instalação de revestimentos (tubo cego). Não se observou na área poços captando águas unicamente do manto de intemperismo.

O nível da água nos poços na região de Remígio localiza-se abaixo do topo do maciço cristalino (Fig. 5). Em Areia e Alagoinha o nível da água se ajusta próximo a base do manto de intemperismo, esse cenário aponta para a importância da cobertura sedimentar no aporte e recarga de água para o aquífero fraturado nesse setor. O pacote sedimentar capeador não constitui um aquífero propriamente dito, e sim uma unidade de transferência vertical de águas de para o maciço rochoso subjacente.
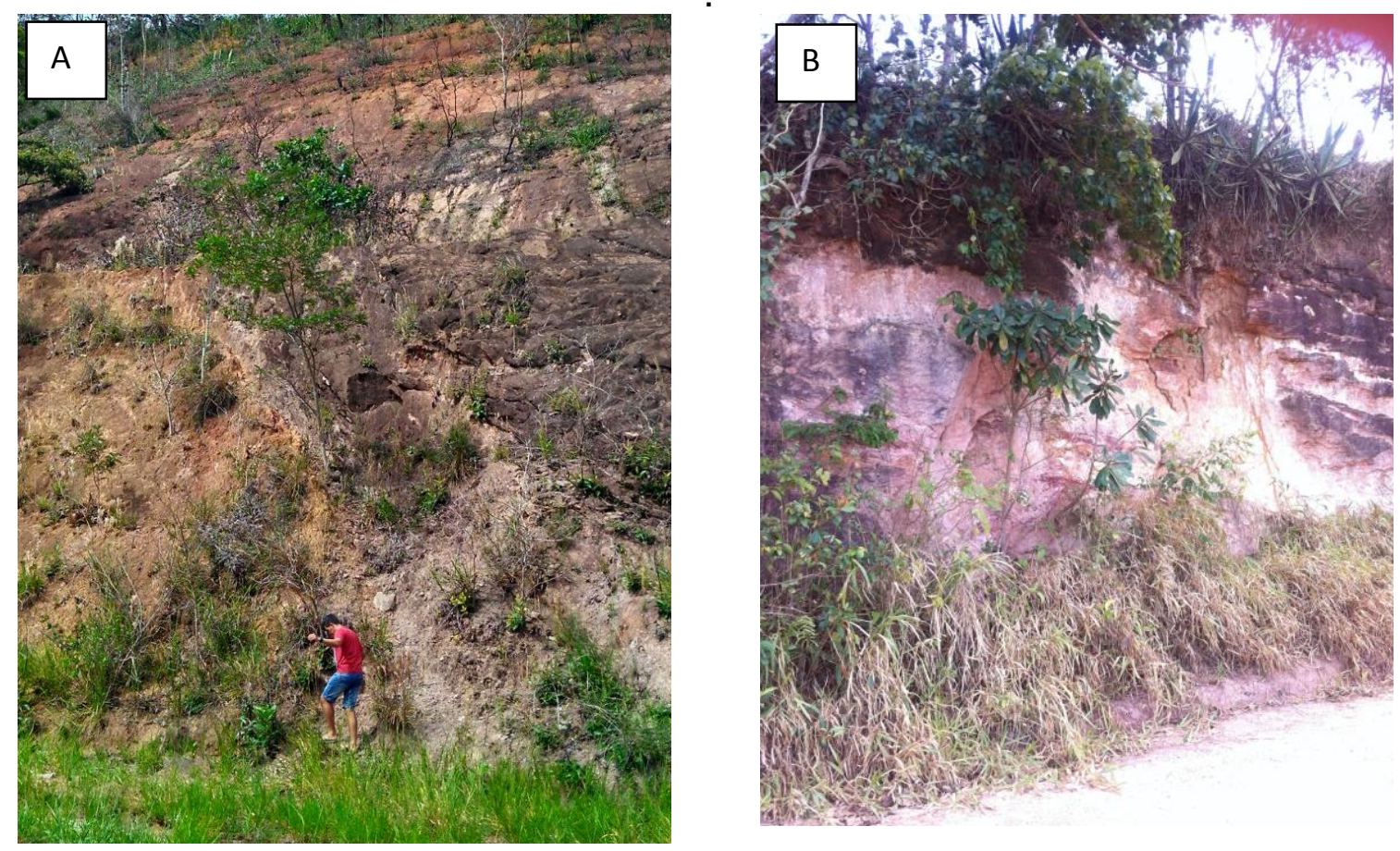

Figura 4 - Aspectos geológicos do município de Areia. A) Manto de intemperismo desenvolvido a partir da alteração das rochas do embasamento cristalino. B) Afloramentos da Formação Serra dos Martins, composta por arenitos.

$\mathrm{E}$

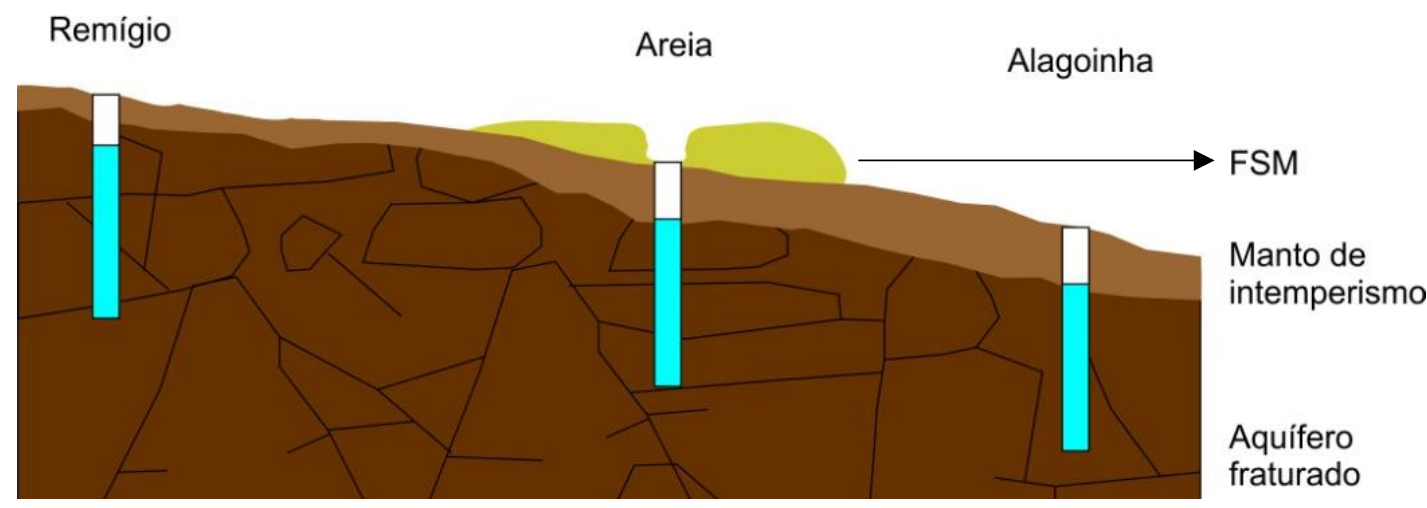

Figura 5 - Perfil hidrogeológico esquemático da área de estudo, elaborado a partir dos perfis litológicos obtidos na base do SIAGAS/CPRM. 
A FSM no município de Areia assume espessuras da ordem de 10 metros, em média. Os perfis litológicos e construtivos analisados apontam que os poços perfurados na área interceptam apenas alguns poucos metros nessa formação, de forma que essas captações a nível local estão situados nos baixos topográficos, onde a FSM tem menor espessura. Convém ressaltar, que a presença regional dessa formação parece influenciar de forma positiva na transferência de águas para o aquífero fraturado. Não se observou na área poços captando águas unicamente da FSM, mas não fica descartada essa ocorrência.

A produtividade do aquífero foi avaliada através das informações de vazão dos poços, e evidenciaram uma grande variabilidade nos resultados (Fig. 6). Foram registradas desde vazões insignificantes (inferior a 0,1 $\mathrm{m}^{3} / \mathrm{h}$ ) até de $12 \mathrm{~m}^{3} / \mathrm{h}$, refletindo numa média da ordem $1,5 \mathrm{~m}^{3} / \mathrm{h}$ (Tabela 1) para a área toda.

Nos municípios de Esperança, Remígio, Arara e Serraria os poços produzem vazões médias inferiores a $0,6 \mathrm{~m}^{3} / \mathrm{h}$ (Tabela 1). Nesse setor também são verificadas as menores precipitações pluviométricas do trecho estudado (Fig. 2). Os municípios de Alagoa Nova e Pilões se destacam com as maiores vazões média dos poços, da ordem de 2,2 e 4,3 $\mathrm{m}^{3} / \mathrm{h}$, respectivamente, podendo atingir 12 $\mathrm{m}^{3} / \mathrm{h}$ no município de Pilões (Tabela 1 ). Nessa área, além das maiores precipitações pluviométricas verificadas, a cobertura sedimentar (manto de intemperismo e Fm. Serra dos Martins) (Fig.4) possui maiores espessuras. Esse cenário corrobora com a maior produtividade no setor, onde as coberturas sedimentares favorecem 0 aporte de águas de recarga para o aquífero fraturado captado.

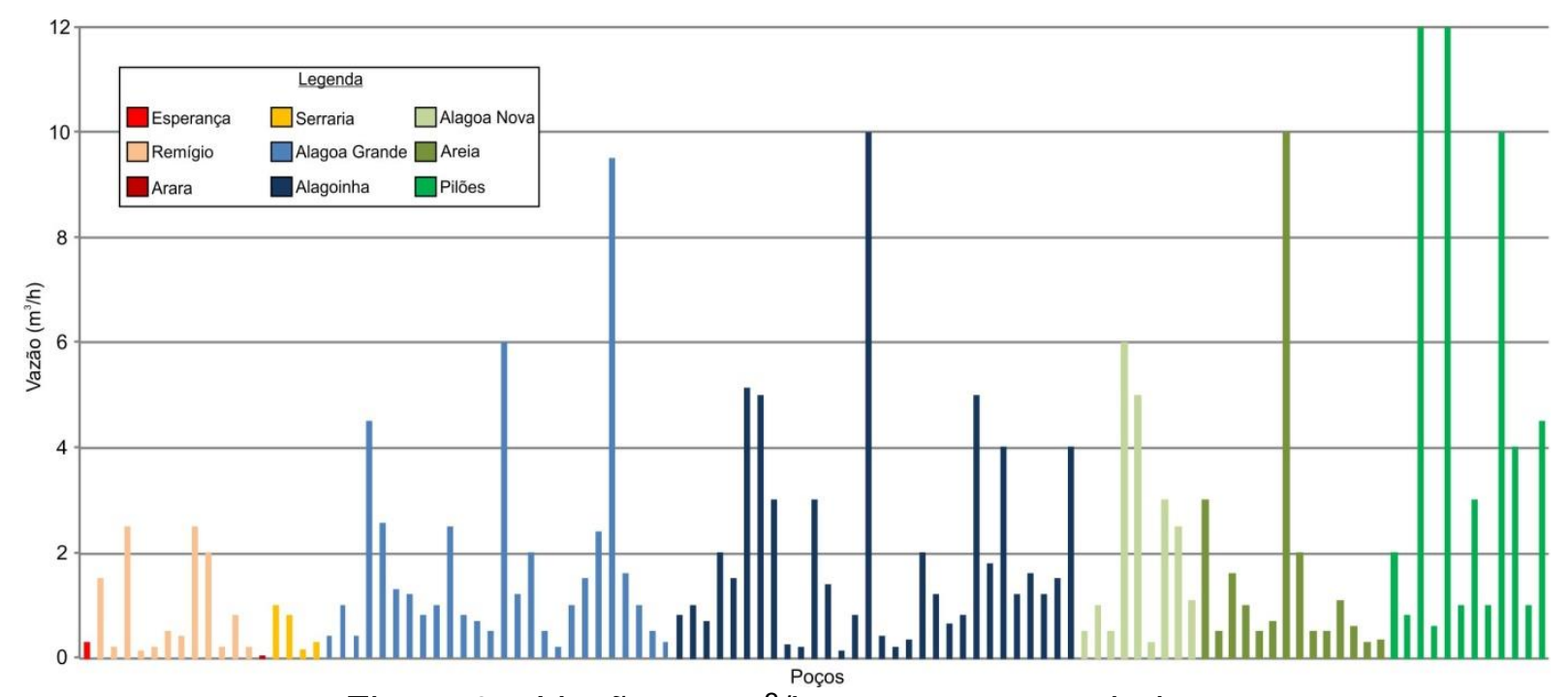

Figura 6 - Vazão em $\mathrm{m}^{3} / \mathrm{h}$ nos poços estudados. 
Tabela 1 - Sumário estatístico da vazão dos poços em cada município.

\begin{tabular}{|l|c|c|c|c|}
\hline \multirow{2}{*}{ Município } & \multirow{2}{*}{$\begin{array}{c}\text { Número de } \\
\text { poços }\end{array}$} & Mínimo & Máximo & Média \\
\cline { 3 - 5 }$\left(\mathrm{m}^{3} / \mathrm{h}\right)$ \\
\hline Esperança & 1 & \multicolumn{3}{|c|}{0,3} \\
\hline Remígio & 12 & 0,1 & 2,5 & 0,5 \\
\hline Arara & 1 & \multicolumn{3}{c|}{0,03} \\
\hline Serraria & 4 & 0,2 & 1 & 0,6 \\
\hline Alagoa Grande & 26 & 0,2 & 9,5 & 1,7 \\
\hline Alagoinha & 30 & 0,1 & 10 & 2 \\
\hline Alagoa Nova & 9 & 0,3 & 6 & 2,2 \\
\hline Areia & 14 & 0,3 & 10 & 1,6 \\
\hline Pilões & 12 & 0,6 & 12 & 4,3 \\
\hline & \multicolumn{5}{|c|}{ Vazão média $(\mathrm{n}=109)$} & 1,47 \\
\hline
\end{tabular}

\section{Salinidade das águas subterrâneas}

A avaliação da salinidade das águas subterrâneas na área de estudo foi baseada no parâmetro Sólidos Totais Dissolvidos (STD), e conforme classificação proposta por McNeely et al., 1979 (Tabela 2). Dentre os 180 poços considerados, o STD variou de 100 a $22912 \mathrm{mg} / \mathrm{L}$ (Tabela 3), variando desde águas Doces à Salgadas, refletindo no valor médio de 3467,66 $\mathrm{mg} / \mathrm{L}$, que se enquadra na classe de águas moderadamente salobras. Predominam águas Doces em $42 \%$ dos poços, seguido das águas Moderadamente salobras (25\%), Ligeiramente salobras (22\%), e em menor proporção encontram-se águas Salgadas (11\%), conforme apresentado na Figura 7. A legislação brasileira adota como referencial de Valor Máximo Permitido (VMP) para as águas de consumo humano o limiar de $1000 \mathrm{mg} / \mathrm{L}$ de STD (BRASIL, 2011).

Tabela 2 - Classificação da salinidade das águas conforme o teor de Sólidos Totais Dissolvidos (STD) (McNeely et al., 1979)

\begin{tabular}{|c|c|}
\hline Tipo & STD $(\mathrm{mg} / \mathrm{L})$ \\
\hline Doces & $<1000$ \\
\hline Ligeiramente salobras & $1000-3000$ \\
\hline Moderadamente salobras & $3000-10000$ \\
\hline Salgadas & $10000-100000$ \\
\hline Salmouras & $>100000$ \\
\hline
\end{tabular}

Tabela 3 - Sumário estatístico da salinidade das águas na área de estudo, observada através do parâmetro Sólidos Totais Dissolvidos (STD mg/L) $(n=180)$

\begin{tabular}{|c|c|}
\hline Parâmetro & STD $(\mathrm{mg} / \mathrm{L})$ \\
\hline Mínimo & 100,00 \\
\hline Máximo & 22912,00 \\
\hline Média & 3467,66 \\
\hline
\end{tabular}




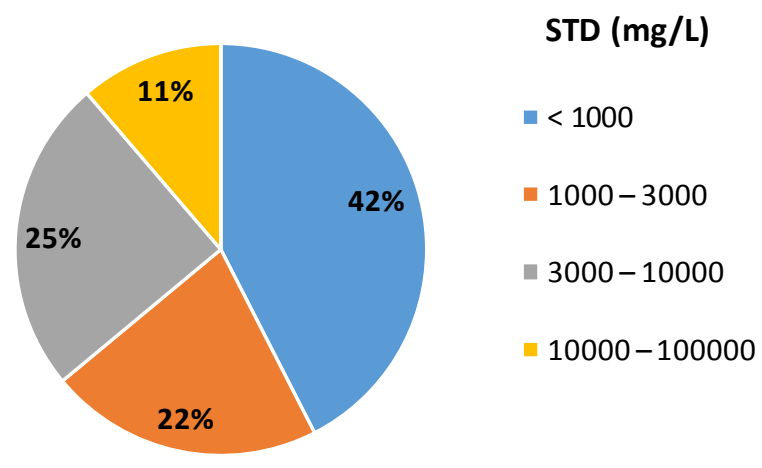

Figura 7 - Distribuição do percentual de poços nos intervalos de Sólidos Totais dissolvidos (STD mg/L).

A Fig. 8 apresenta a distribuição das classes de águas em função do teor STD em cada município. Em Pilões, Alagoa Nova e Areia predominam águas Doces (STD inferior a 1000 $\mathrm{mg} / \mathrm{L})$. Em Alagoinha e Alagoa Grande a maioria dos poços apresentam salinidade inferior a $3000 \mathrm{mg} / \mathrm{L}$ de STD, portanto classificadas como Ligeiramente salobras a Doces. Em Esperança, Arara e Serraria predominam águas Salgadas, com salinidade superior a $3000 \mathrm{mg} / \mathrm{L}$ de STD.

A distribuição espacial do parâmetro STD da Fig. 9 demonstra que no setor Leste, entre Alagoinha e Alagoa Grande, predominam águas com salinidade baixa a intermediária. $\mathrm{Na}$ faixa central, entre os municípios de Pilões, Areia e Alagoa Nova, as águas apresentam baixa salinidade, isto é, são Doces (inferior a $1000 \mathrm{mg} / \mathrm{L}$ ). As maiores concentrações de STD ocorrem na faixa Norte e Noroeste, entre os municípios de Serraria, Arara, Remígio e Esperança, que apresentam águas com elevados valores de STD, onde predominam as Moderadamente salobras a Salgadas (Tabela 2).
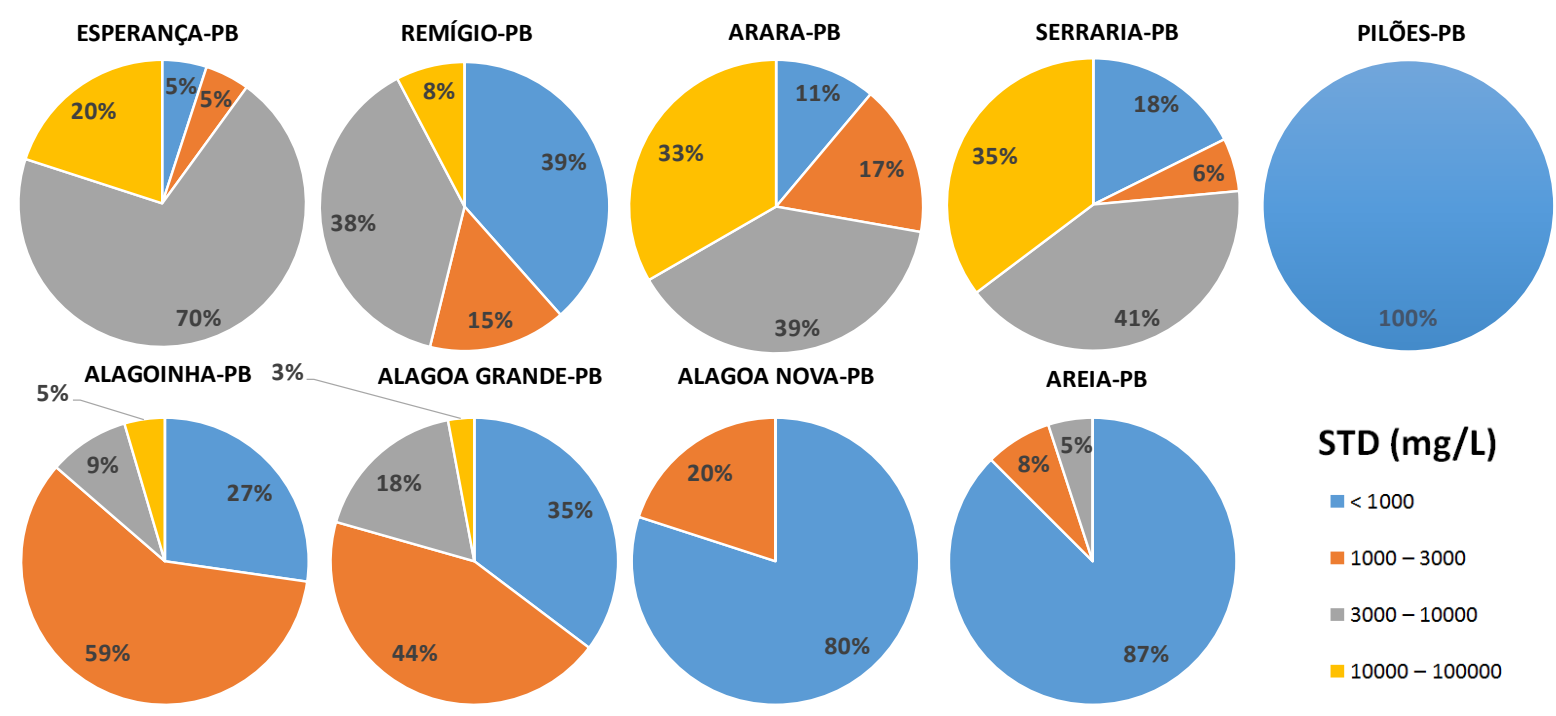

AREIA-PB
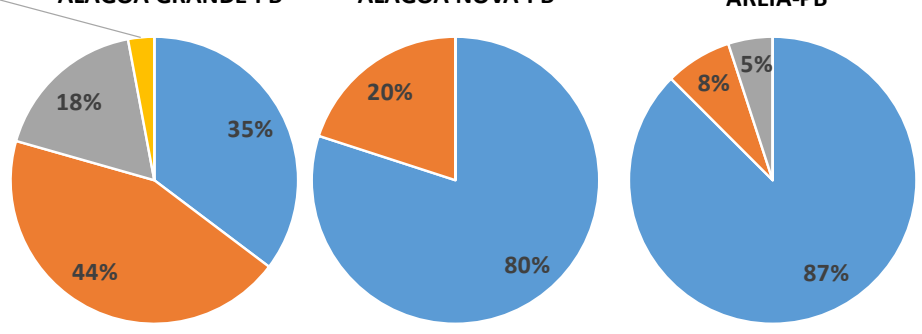

STD (mg/L)

- $<1000$

$\square 1000-3000$

- $3000-10000$

$10000-100000$

Figura 8 - Gráficos de distribuição de Sólidos Totais Disponíveis (STD mg/L) em cada município. 


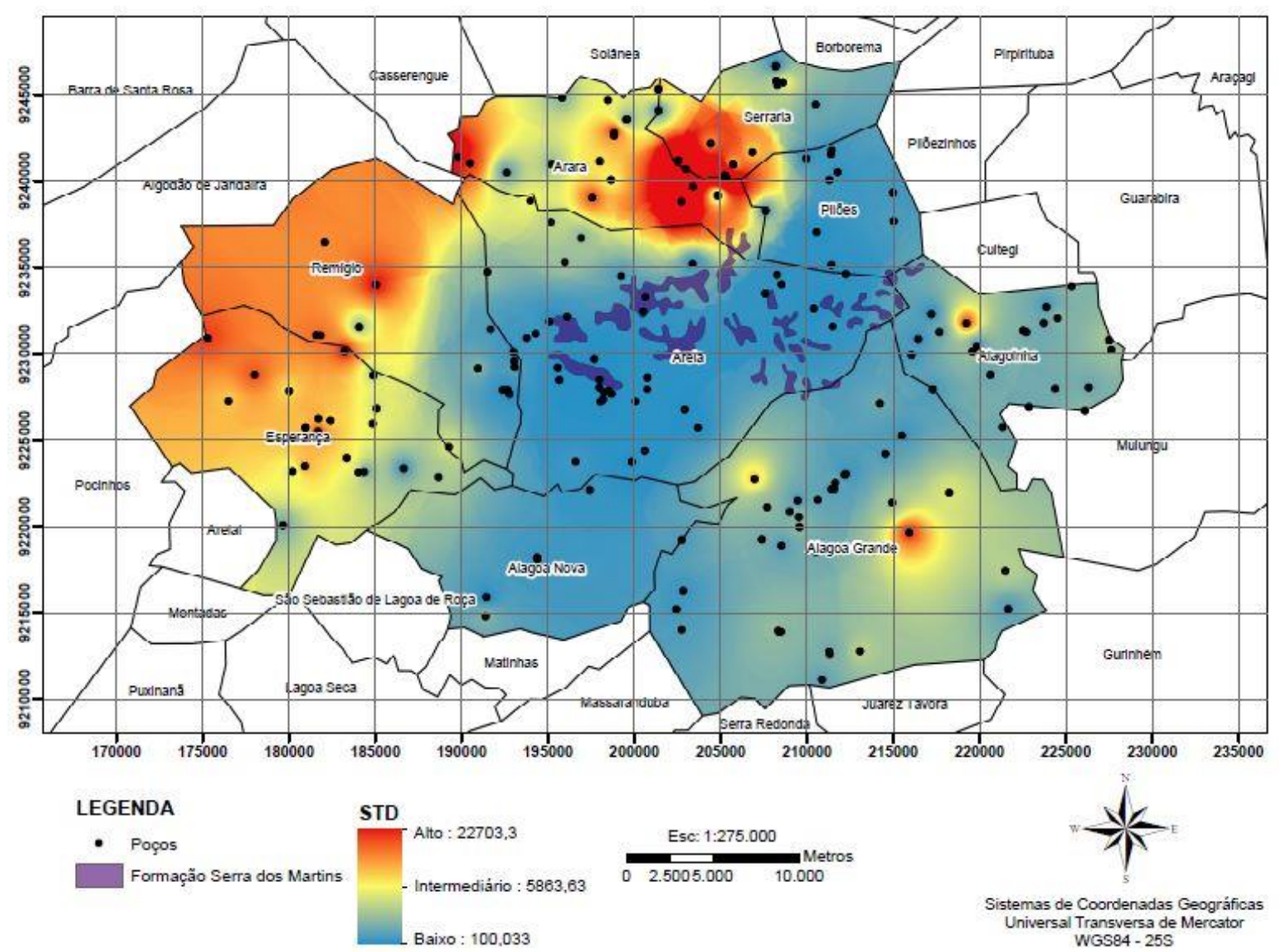

Figura 9 - Isovalores de Sólidos Totais Disponíveis (STD mg/L) das águas subterrâneas na área de estudo.

\section{Zoneamento da área}

$\mathrm{Da}$ integração dos dados geológicos, hidrogeológicos, fisiográficos e de salinidade das águas do aquífero fraturado foi possível zonear a área de estudo em três setores com características distintas, os quais:

\section{$\underline{\text { Setor Oeste }}$}

Abrange os municípios de Esperança, Remígio, Arara e Serraria, onde foram estudados 68 poços.

A precipitação pluviométrica média anual neste setor é da ordem de $800 \mathrm{~mm}$, representando a menor taxa de chuvas dos três setores individualizadas. $O$ déficit de chuvas ocorre pelo efeito orográfico, onde a altitude no setor é superior aos 600 metros (Fig. 3) e as massas de ar que migram de Leste para Oeste precipitam no ápice da Serra de Areia (região central), provocando assim uma escassez de chuvas na faixa Oeste. Associado ao fator climático observase, de modo geral, fragmentos florestais mais escassos neste setor (Fig.3). A camada de solo e/ou manto de intemperismo, quando presente, sobrejacente ao embasamento cristalino é pouco espesso, inferior a 5 metros (Fig. 5). Todo esse cenário explica a baixa produtividade do aquífero fraturado no setor, cujos poços desenvolvem vazões de até $2,5 \mathrm{~m}^{3} / \mathrm{h}$, refletindo numa média de $0,33 \mathrm{~m}^{3} / \mathrm{h}$ (Fig. 6 e Tabela 1). Predominam águas Moderadamente salobras seguidas de águas Salgadas (Figs. 8 e 9)

\section{Setor Leste}


Compreende os municípios de Alagoa Grande e Alagoinha, onde foram analisados 56 poços.

A média de precipitação pluviométrica total é de aproximadamente $1000 \mathrm{~mm}$ ao ano, o que representa uma taxa de incidência de chuvas intermediária, quando comparada às demais áreas individualizadas. A altitude nesse setor é a menor dentre as porções individualizadas: inferior a 300 metros (Fig. 3). A cobertura vegetal nesse domínio ocorre de forma esparsa, quando comparado aos demais domínios estudados. Um adensamento florestal se verifica no limite oeste dos municípios, em direção a escarpa da Serra de Areia, onde as condições fisiográficas favorecem o aumento das chuvas. Nesse setor, o manto de rocha intemperisada sobrejacente ao embasamento cristalino apresenta espessura de até 20 metros (Fig. 5). Os poços produzem vazões de até 10 $\mathrm{m}^{3} / \mathrm{h}$, refletindo numa média de 1,85 $\mathrm{m}^{3} / \mathrm{h}$ (Fig. 6 e Tabela 1). Predominam águas ligeiramente salobras seguidas de águas Doces, portanto com STD inferior a 3000 mg/L (Figs. 8 e 9). Estes poços captam águas do aquifero fraturado, e o manto de intemperismo sobrejacente encontra-se isolado através de tubulação cega. Convém ressaltar que não se observa nesse setor poços instalados no manto intemperisado.

\section{Setor Central}

Entre os municípios de Alagoa Nova, Areia e Pilões, foram avaliadas informações de 56 poços.

A média da precipitação pluviométrica nesse setor é da ordem de $1200 \mathrm{~mm} / \mathrm{ano}$, a maior dentre as três áreas individualizadas. A ocorrência das chuvas se dá devido a presença da Serra de Areia (Formação Serra dos Martins, na Fig. 3) localizada no município homônimo, que favorece as condições de instabilidade meteorológica, e consequentemente o maior desenvolvimento da vegetação: os brejos de altitude do Nordeste (Fig. 3). A cobertura sedimentar na área (FSM e manto de intemperismo nas Figs. 4 e 5), que capeia o embasamento cristalino, favorece as condições de infiltração e armazenamento das águas de recarga no aquifero fraturado. A presença da vegetação na superfície do solo também contribui na percolação da água das chuvas em direção ao subsolo. Nesse contexto, a produtividade hidrogeológica dos poços do aquífero fraturado assume valores de vazão de até $12 \mathrm{~m}^{3} / \mathrm{h}$, com média de $2,7 \mathrm{~m}^{3} / \mathrm{h}$, a maior dos três setores diferenciados (Fig.6 e Tabela 1). Aliado a maior potencialidade hidrogeológica, observa-se o predomínio de águas Doces, com salinidade inferior a 1000 mg/L de STD (Fig. 8 e 9).

\section{CONCLUSÕES}

A produtividade dos poços e a qualidade da água sob o ponto de vista da salinidade, na área de estudo, estão intimamente ligadas ao aspecto geológico, que é caracterizado por maiores elevações topográficas na região central da área, que consequentemente afeta as condições meteorológicas da região. A topografia elevada da Serra de Areia (afloramento da Formação Serra dos Martins) da ordem de 500 metros de altitute, localizada na porção central da área, é responsável pela maior ocorrência de chuvas nesse setor e déficit na faixa oeste. As massas de ar úmido advindas do Atlântico precipitam na Serra e à leste dela, acarretando na deficiência de chuvas à oeste, impondo a esse setor características de regiões semiáridas e de vegetação escassa.

As chuvas na porção central regulam a recarga local das águas 
subterrâneas armazenadas no aquífero fraturado. O manto de intemperismo e a FSM desempenham um papel importante dentro desse contexto. Conjuntamente formam a zona não saturada que, por encontrar-se em contato direto sobre a rocha, favorecem as condições de recarga e armazenamento do aquífero fraturado e tb funcionam como proteção à evaporação direta; reduzindo a salinidade. Ainda, a presença de vegetação de Brejos de Altitude proporciona melhores condições de infiltração ao subsolo na medida em que diminuem o escoamento superficial. Uma maior renovação de águas de recarga beneficia a ocorrência de águas Doces (STD $<1000$ $\mathrm{mg} / \mathrm{L}$ ) nesse domínio. Recomenda-se em estudos futuros um aprofundamento dos aspectos geológicos visando, por exemplo, avaliar a presença de estruturas geológicas que podem estar contolando o aquifero fissuram na área, tais como falhas e zonas de cisalhamento, que tornaria as rochas mais fraturadas ou com uma anisotropia mais marcante, e portanto favorecendo a potencialidade hidrogeológica setorizada.

Agradecimentos A Unidade Acadêmica de Mineração e Geologia da UFCG que disponibilizou recursos para as visitas de campo. Aos revisores do periódico que contribuíram significativamente no manuscrito final.

\section{REFERÊNCIAS}

AB'SABER, A. N.,1970. Províncias geológicas e domínios morfoclimáticos no Brasil. Biomorfologia 20: 1-26.

AESA - AGÊNCIA EXECUTIVA DE GESTÃO DAS ÁGUAS DO ESTADO DA PARAÍBA. 2016. Disponível em: http://www.aesa.pb.gov.br/aesawebsite/meteorologia-

chuvas/Acesso em: 25 de novembro de 2016.

ALMEIDA, F. F. M. de. 1969. Diferenciação tectônica da plataforma brasileira. In: Congresso Brasileiro de Geologia, 23, 1969, Salvador. Anais do... 273p. p.29-46.

ANA - AGÊNCIA NACIONAL DE ÁGUAS. Monitor de Secas do Nordeste do Brasil. 2017. Disponível em: $<$ http://monitordesecas.ana.gov.b r/>. Acesso em: 10 de abril de 2017.

BRASIL. Ministério da Integração. Nova Delimitação do Semiárido Brasileiro. 2005. Disponível em: $<$ http://www.museusemiarido.org. br/expedicao/cartilha_delimitacao semi_arido.pdf>. Acesso em: 10 de abril de 2017.

BRASIL. Ministério da Saúde. Portaria $\mathrm{n}^{\circ} 2914$ de 12 de dezembro de 2011. Dispõe sobre os procedimentos de controle e de vigilância da qualidade da água para consumo humano e seu padrão de potabilidade. 2011. Disponível em: <http://bvsms.saude.gov.br/bvs/s audelegis/> Acesso em: 19 de novembro de 2016.

CPRM - SERVIÇO GEOLÓGICO DO BRASIL. Sistema de informação de águas subterrâneas (SIAGAS). 2006. Disponível em: <http://siagasweb.cprm.gov.br/lay out/pesquisa_complexa.php> Acesso em: 10 de dezembro de 2016.

DINIZ, J. A. O.; MONTEIRO, A. B.; SILVA, R. C.; DE PAULA, T. L. F., 2014. Mapa Hidrogeológico do Brasil ao Milionésimo. Recife, PE. Programa de Cartografia Hidrogeológica. Companhia de Pesquisa de Recursos Minerais 
(CPRM) - Serviço Geológico do Brasil.

MCNEELY, R. N., NEIMANIS, V. P., \& DWYER, L., 1979. Water quality sourcebook: A guide to water quality parameters. In Water Quality Sourcebook: A guide to water quality parameters. Environment Canada.

MDA - Ministério do Desenvolvimento Agrário. Plano Territorial de Desenvolvimento Rural Sustentável - Território da Borborema-PB. Resumo Executivo 2010-2020. Paraíba. $2010 . \quad$ Disponível em: <http://sit.mda.gov.br/download/pt drs/ptdrs_qua_territorio024.pdf> Acesso em: 23 de abril de 2017.
MENEZES, M.R.F., 1999. Estudos sedimentológicos e o contexto estrutural da Formação serra do Martins, nos platôs Portalegre, Martins e Santana/RN. Dissertação de Mestrado apresentada na Universidade Federal do Rio Grande do Norte.

SANTOS, E. J.; FERREIRA, C.A.; SILVA, J.M.F.Jr., 2002. Geologia e recursos minerais do Estado da Paraíba, CPRM, Recife. 